\title{
OS ECHINOIDEA (ECHINODERMATA) DA LOCALIDADE CATETE VELHO I (CRETÁCEO) EM SERGIPE, NORDESTE DO BRASIL
}

\author{
CYNTHIA LARA DE CASTRO MANSO \& ANA CAROLINA COSTA LEMOS \\ Universidade Federal de Sergipe, Campus Prof. Alberto Carvalho, Av. Vereador Olímpio Grande s/n, 49500-000, \\ Itabaiana, SE, Brasil.cynthia@phoenix.org.br
}

\begin{abstract}
RESUMO - Foram identificadas cinco espécies de equinóides na localidade Catete Velho 1, Formação Riachuelo, bacia de Sergipe-Alagoas. Destas, Temnocidaris (Stereocidaris) malheiroi, Orthopsis miliaris, Leptosalenia sergipensis e Phymosoma binexilis teriam se distribuído em grupos ecológicos com base nas suas estratégias alimentares. Coenholectypus neocomiensis, teria vivido no interior de sedimentos permeáveis identificados como areia grossa ou cascalho. De acordo com as características morfológicas das carapaças, tais como filódios estreitos ou mesmo sem filódios, estes organismos provavelmente teriam vivido em um ambiente raso, calmo e protegido, durante o Albiano Médio.
\end{abstract}

Palavras-chave: Equinóides, Formação Riachuelo, Albiano Médio, bacia de Sergipe-Alagoas.

\begin{abstract}
THE ECHINOIDEA (ECHINODERMATA) FROM CATETE VELHO 1 LOCALITY (CRETACEOUS) IN SERGIPE, NORTHEASTERN BRAZIL. Five species of fossil echinoids were identified at the Catete Velho 1 locality, in rocks from the Riachuelo Formation, Sergipe-Alagoas Basin. Among them, Temnocidaris (Stereocidaris) malheiroi, Orthopsis miliaris, Leptosalenia sergipensis and Phymosoma binexilis would have been distributed in ecological groups based on their feeding strategies. Coenholectypus neocomiensis would have been infaunal in coarse permeable sands and a particle feeder. According to the morphological characteristics of the species, such as narrow or even absent phyllodes, these organisms probably would have lived in shallow, quiet and protected environment, during the Middle Albian.
\end{abstract}

Key words: Echinoids, Riachuelo Formation, Middle Albian,Sergipe-Alagoas Basin.

\section{INTRODUÇÃO}

Os depósitos cretácicos brasileiros aflorantes na região nordeste do país compõem bacias com excelente conteúdo fossilífero marinho, possibilitando o estudo de invertebrados fósseis, com destaque para os equinodermos. Assim como as espécies atuais, estes organismos compunham a fauna bentônica e, devido à sua direta interrelação com o substrato, tornam-se bons indicadores em estudos paleoambientais.

Fósseis de equinodermos de idade cretácica foram registrados originalmente no Brasil por White (1887) e posteriormente revisados por Maury (1937), com a descrição de novas espécies. Posteriormente, a sistemática de diversas espécies fósseis de equinóides, incluindo aquelas da Formação Riachuelo de Sergipe, foi revisada por Brito (1964, 1980, 1981a, 1981b), Brito \& Ramirez, (1974) e Smith \& Bengtson (1991), com algumas novas ocorrências para os depósitos cretácicos de Sergipe. Estudos mais recentes sobre os equinóides da bacia de Sergipe-Alagoas enfocaram a ocorrência, a distribuição, sistemática, a paleoecologia e a paleobiogeografia de algumas espécies (Manso, 2003; Manso \& Souza-Lima, 2003a,b, 2005).

Esse trabalho tem por objetivos registrar, pela primeira vez, a ocorrência de equinodermos em rochas mesoalbianas da Formação Riachuelo, da localidade fossilífera Catete Velho 1 (Figura 1) e tecer considerações sobre o provável paleoambiente em que teriam vivido.

\section{GEOLOGIA DA ÁREA ESTUDADA}

A margem continental do Brasil possui uma série de bacias sedimentares, resultantes da deposição sucessiva de carbonatos, como resultado da ruptura da placa africanasulamericana (Koutsoukos et al., 1993). Entre estas, se encontra a bacia de Sergipe-Alagoas, nos estados homônimos. Em Sergipe, a metade meridional da bacia contém a seqüência neomesozóica quase completa, apresentando falhas apenas nas áreas marginais. Desta forma, a história geológica desta bacia é compatível com o desenvolvimento tectônico, em seus diversos estágios de separação dos continentes africano e sul-americano (Ojeda \& Fujita, 1976).

A Formação Riachuelo tem espessura relativamente uniforme, em torno de 500 m, e é sobreposta à Formação Muribeca, que não aflora em superfície e está coberta pelos calcários da Formação Cotinguiba (Schaller, 1970). Engloba um complexo clástico carbonático onde podem ser reconhecidos três membros: Angico, Taquari e Maruim (Feijó, 1995). O Membro Angico, que corresponde à base da formação, é dominantemente terrígeno, composto por arenitos finos a conglomeráticos com contribuição bioclástica e calciruditos bioclásticos, depositados em sistemas de leques costeiros subaquosos. O Membro Taquari, intermediário, caracteriza-se pelo aumento no percentual de carbonatos em direção ao topo, sendo composto por intercalações de calcilutitos e folhelhos cinzentos, interpretados como que 


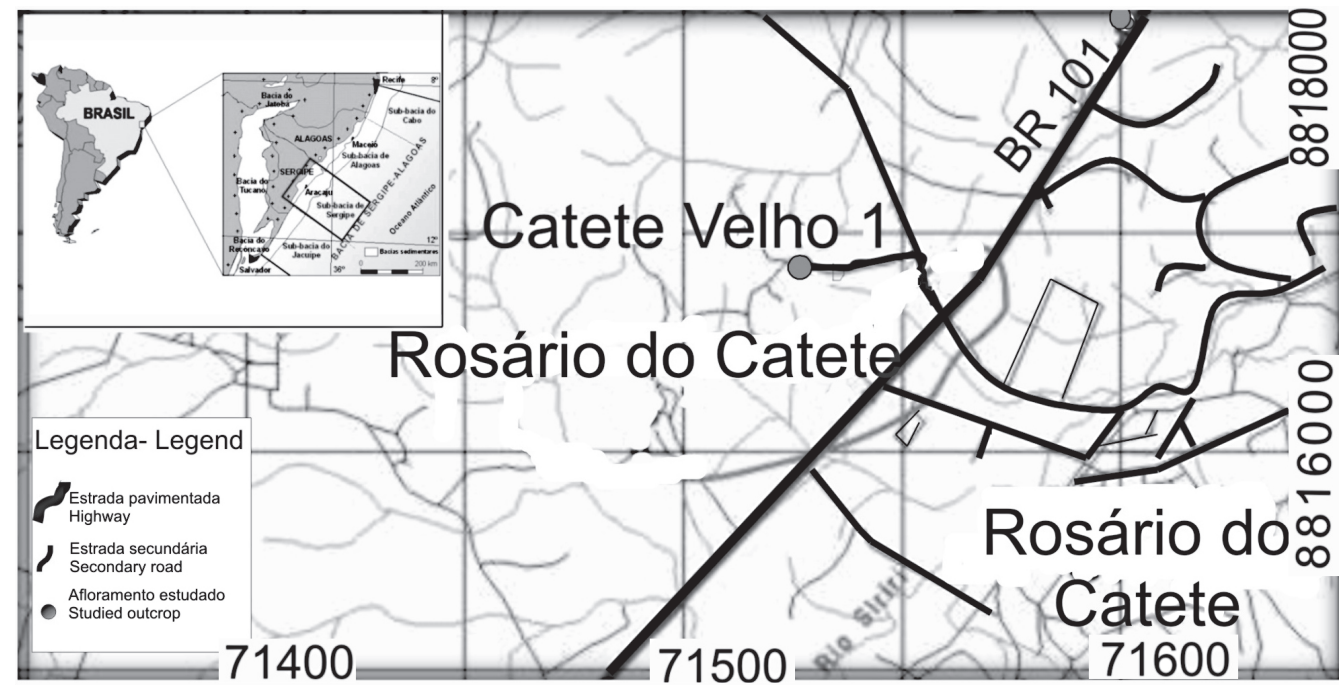

Figura 1. Mapa de localização do afloramento Catete Velho 1.

Figure 1. Location map of the outocrop Catete Velho 1.

depositados em áreas calmas da bacia, ao redor do Membro Maruim ou entremeados com os clásticos do Membro Angico. O Membro Maruim constitui-se de calcarenitos, calciruditos oncolíticos e/ou calcários oolíticos com contribuição bioclástica, recifes algálicos e "patch reefs" isolados, e representa depósitos de ambientes costeiros de alta energia (Schaller, 1970, Reis et al., 2005). O estudo de microfósseis da Formação Riachuelo sugere a persistência de ambientes lagunares até o Mesoalbiano (Koutsoukos et al., 1991). A diversificada e abundante fauna de micromoluscos, sugere condições hipersalinas das águas de fundo dessas lagunas desde o início dos eventos de abertura do Oceano Atlântico Sul até a metade do Albiano. Estudos tem demonstrado a presença de uma rica fauna fóssil de invertebrados marinhos nas rochas do Membro Maruim (Manso, 2003; Manso \& Souza-Lima, 2003, 2005; Reis et al. 2005; Lemos \& Manso, 2007), com destaque para os equinodermos.

Localidade. O afloramento estudado (Figura 1) pertence a camadas do Albiano Médio, zona do amonóide Oxytropidoceras (Manso, 2003) e está situado no Município de Rosários do Catete. Esta localidade foi descrita utilizandose a metodologia adotada por Bengtson (1983). O código Krm corresponde a Formação Riachuelo, Membro Maruim. Seção corresponde a afloramento com altura superior a $0,5 \mathrm{~m}$.

Catete Velho 1. UTM 8.817.850N/713.550E. Folha SC.24-Z-BIV- 4 Aracaju. Seção exposta em pedreira com acesso defronte à entrada da cidade de Rosário do Catete no município de mesmo nome. Krm: Calcário bioclástico oncolítico e/ou oolitico com abundantes equinóides da espécie Orthopsis miliaris, grandes moluscos bivalves e Neithea. Referências: Manso (2003), Lemos \& Manso (2007).

\section{MATERIAL E MÉTODOS}

O material estudado pertence à coleção de invertebrados fósseis da Fundação Paleontológica Phoenix (FPPH), e foram cedidos ao Laboratório de Invertebrados Marinhos (LABIMAR) da Universidade Federal de Sergipe, Campus de Itabaiana, para estudo.
Os fósseis foram preparados e identificados por comparação com a bibliografia especializada, tendo sido descritos apenas os espécimes com melhor estado de preservação. Para a descrição, foram tomadas medidas do diâmetro e da altura das carapaças com auxílio de paquímetro digital da marca Miyutoyo, com precisão de $0,1 \mathrm{~mm}$. Para facilitar o estudo, foram adotados os termos "regular", para todas as formas radialmente simétricas, e "irregular", para as formas com simetria bilateral, independente das relações.

As interpretações paleoecológicas foram baseadas na análise morfológica das características das carapaças apresentadas, de acordo com Smith (1984, 1995), Néraudeau et al (1993) e Manso (2003).

As coordenadas de localização da área fonte dos fósseis foram obtidas utilizando-se um GPS sobre o datum Córrego Alegre, convertidas para o datum Aratu e arredondadas para os $50 \mathrm{~m}$ mais próximos. As coordenadas UTM estão referenciadas ao meridiano central $39^{\circ}$. Convém ressaltar que os fósseis foram coletados soltos ao pé da pedreira que na época da coleta estava ativa.

\section{SISTEMÁTICA PALEONTOLÓGICA}

\author{
Classe ECHINOIDEA Leske, 1778 \\ Subclasse CIDAROIDEA Claus, 1880 \\ Ordem CIDAROIDA Claus, 1880 \\ Temnocidaris (Stereocidaris) malheiroi (Loriol, 1888)
}

\section{Material. FPH-839-I}

Distribuições geográfica e estratigráfica. Espécie conhecida do Albiano superior da bacia de Benguela, Angola e do Albiano Superior da Formação Riachuelo, Sergipe. Amplia aqui a distribuição estratigráfica conhecida para o Albiano médio da bacia de Sergipe.

Carapaça. Placas da região ambulacral e interambulacral unidas, demonstrando ter sido a carapaça globular e levemente deprimida no terço inferior abaixo do âmbitus.

Região apical. Ausente

Região ambulacral. Levemente sinuosa e formada por placas 
com 4,0 mm de largura. Os pares de poros ambulacrais são subconjugados a não conjugados, separados por uma partição interporal, que ocupa mais da metade da placa ambulacral. Estes poros estão posicionados de forma sucessiva, bastantes próximos uns dos outros. O conjunto está adjacente a um único tubérculo primário com mamelão. O restante da placa está preenchido por duas fileiras horizontais de pequenos tubérculos, normalmente em número de dois a seis.

Região interambulacral. É composta por duas colunas de placas com formatos pentagonais, mais altas do que largas, sendo que uma delas possui seis placas e a outra, sete. A coluna que possui sete placas apresenta um tubérculo rudimentar na primeira placa ao lado do sistema apical. As demais placas desta região carregam um tubérculo primário perfurado com a plataforma lisa, e com aureola de 5,0 $\mathrm{mm}$ de diâmetro, sulcada, e que ocupa a maior parte da placa. Envolvendo cada aureola existe um círculo de 14 a 15 tubérculos escrobiculares. O restante da placa está preenchido por muitas fileiras horizontais de grânulos.

Perístoma. Ausente

Subclasse EUECHINOIDEA Bronn, 1860 Infraclasse ACROECHINOIDEA Smith, 1984

Ordem ORTHOPSIDA Mortense, 1942

Família ORTHOPSIDAE Ducan, 1889

Orthopsis miliaris (d'Archiac, 1835)

(Figura 2)
Material. FPH-655-I a FPH-779-I; FPH-803-I; FPH-830-I.

Distribuições geográfica e estratigráfica. Espécie conhecida do Cenomaniano ao Maastrichtiano da Europa, África, Oriente Médio, Estados Unidos. No Brasil a espécie é conhecida do Albiano inferior da Formação Riachuelo ao Cenomaniano médio da Formação Cotinguiba, na bacia de Sergipe.

Carapaça. Carapaças relativamente baixas, de contorno semipentagonal a subcircular medindo entre 10,17 e 42,53 mm de diâmetro, com o âmbitus pouco abaixo da metade da carapaça.

Região apical. Disco apical dicíclico, embora em alguns uma ou outra placa ocular posterior possa estar inserida no disco. Placas genitais semitriangulares com as placas oculares pequenas. Gonoporos pequenos e situados na extremidade posterior da placa genital. O restante desta placa está ocupado por tubérculos pequenos. A placa madrepórita é duas vezes maior que as demais placas e possui muitos poros. O periprocto não é muito grande e possui contorno oval.

Região ambulacral. Estreita e com placas ambulacrais compostas. Estas placas são trigeminadas e possuem os pares de poros unisseriais dispostos em fracos arcos de três, com um pequeno tubérculo entre os poros de cada par. Um tubérculo primário perfurado e não crenulado, grande, ocupa dois dos três elementos em cada placa composta, e dois tubérculos secundários menores ocupam o terceiro elemento da placa. No interior da região ambulacral podem ser observados grânulos próximos à junção das placas.

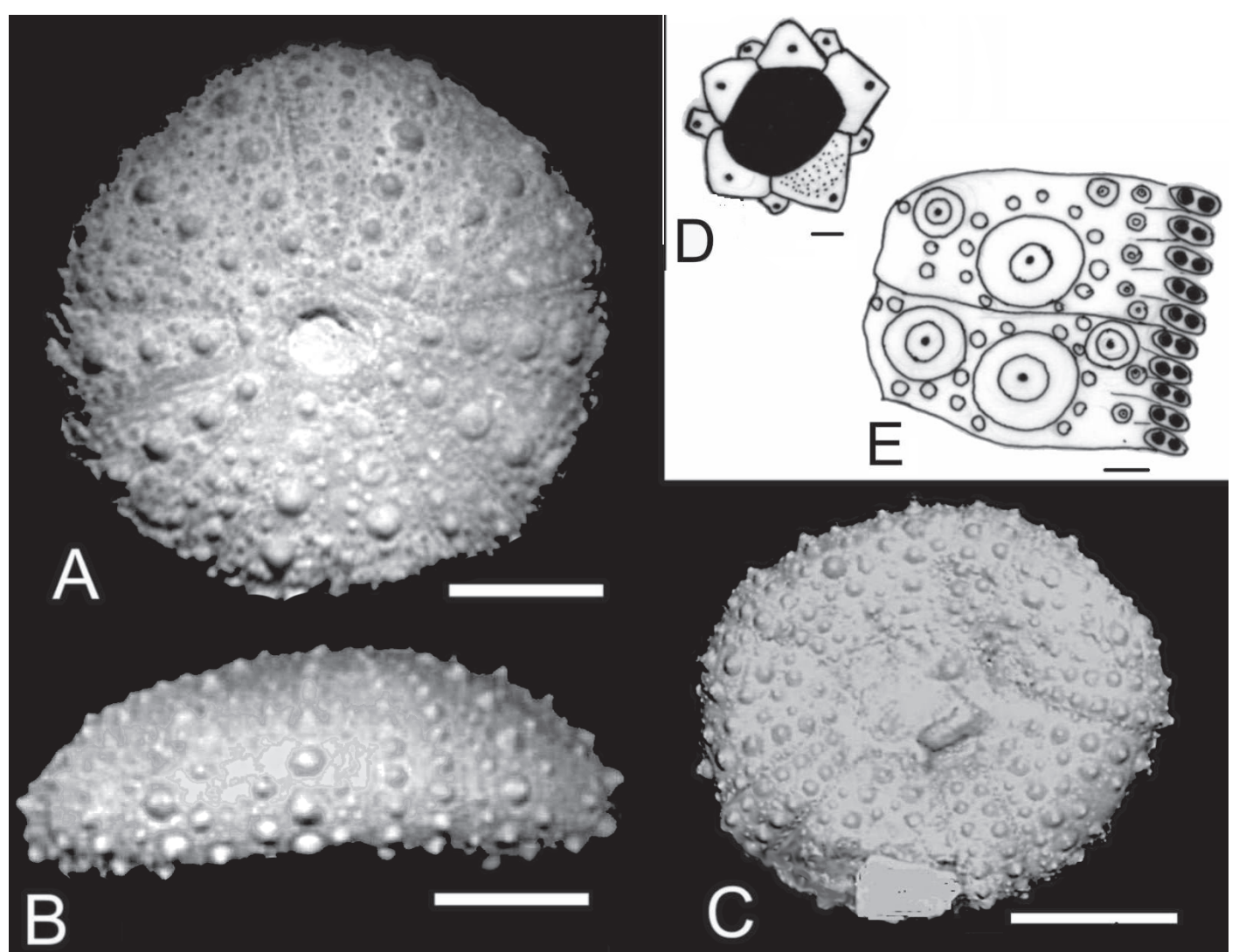

Figura 2. Orthopsis miliaris (FPH-679-I): A, vista dorsal; B, vista lateral; C, vista ventral; D, disco apical; E, placas interambulacrais. Escalas: $A, B=10 \mathrm{~mm} ; C, D=1 \mathrm{~mm}$.

Figure 2. Orthopsis miliaris (FPH-679-I): A, dorsal view; B, lateral view; C, ventral view; D, apical disc; E, interambulacral plates. Scale bars: $A, B, C=10 \mathrm{~mm} ; D, E=1 \mathrm{~mm}$. 
Região interambulacral. É aproximadamente duas vezes mais larga do que a ambulacral com as placas próximas ao âmbitus curtas e largas. Os tubérculos primários são grandes, perfurados e não crenulados, em cada coluna. Próximo ao âmbitus mais duas séries de tubérculos perfurados podem ser observadas: uma próxima à sutura inter-radial e a outra próxima à sutura adradial. Na região ao redor do âmbitus, os tubérculos inter-radiais secundários são quase tão grandes quanto os primários e os adradiais correspondem à metade do tamanho destes. Uma série de tubérculos terciários pequenos está disposta ao redor dos tubérculos primários e secundários (Figura 2D).

Perístoma. É alargado e levemente invaginado, medindo, aproximadamente, $40 \%$ do diâmetro da carapaça nos indivíduos menores e $26 \%$ do diâmetro, nos maiores.

Observações. Alguns exemplares apresentaram aspecto fortemente oval. Deformações de carapaça têm sido observadas em populações de Lytechinus variegatus (Lamark), nas Bermudas, em áreas onde a quantidade de sedimento em suspensão foi aumentada devido à proximidade de regiões onde ocorreram terremotos (Hendler et al., 1995).

Neste afloramento, verificou-se a existência de indivíduos juvenis (carapaça com diâmetro em torno de $10 \mathrm{~mm}$ ). Contudo, o maior número das carapaças encontradas corresponde, provavelmente, a indivíduos adultos, já que seus diâmetros oscilam entre 20,00 e 30,00 mm. Poliquetos (Serpulidae) foram observados associados às carapaças de alguns dos exemplares.

\author{
Ordem CALYCINA Gregory, 1900 \\ Família SALENIIDAEAgassiz, 1838 \\ Tribo SALENIINI Agassiz, 1838 \\ Leptosalenia sergipensis (White, 1887)
}

(Figura 3)

Material. FPH- 806-I a FPH-817-I.

Distribuições geográfica e estratigráfica. Conhecida anteriormente do Albiano superior (Formação Riachuelo) ao Cenomaniano inferior (Formação Cotinguiba) da bacia de Sergipe, e do Albiano médio ao superior de Dombe Grande, Egito e também do Albiano médio ao superior de Cubal, Angola. Amplia-se a distribuição estratigráfica para o Albiano médio de Sergipe.

Carapaça. De contorno circular, com a superfície aboral aplanada e com leve concavidade na superfície oral medindo entre 16,0 e 18,0 mm de diâmetro. O âmbitus nestes indivíduos está localizado no terço inferior da carapaça.

Região apical. Discos apicais pequenos, circulares, lisos e com 11 placas, cujas margens são bem marcadas. As suturas entre as placas podem variar entre pouco definidas, mas com depressões profundas e bem definidas e com depressões suaves. Nos dois modelos, os poros genitais possuem o formato de fechadura e são de tamanho mediano. O madreporito possui três vezes o tamanho dos poros genitais e tem contorno quadrangular na placa genital 2. As placas oculares são triangulares com reentrâncias na margem distal. A placa suranal é desenvolvida, e o periprocto é pequeno,

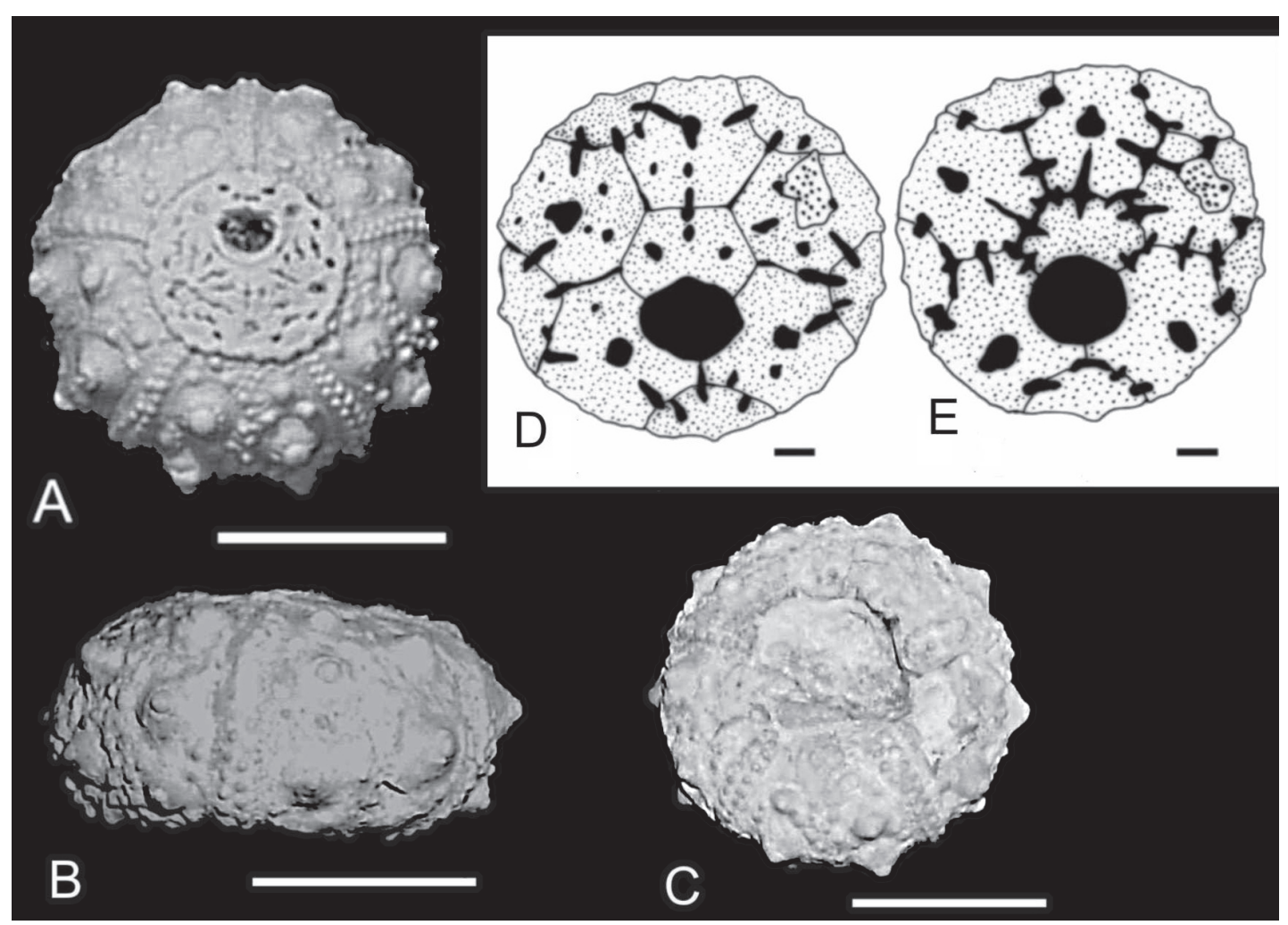

Figura 3. Leptosalenia sergipensis (FPH-806-I) em vistas dorsal $(\mathbf{A})$, lateral $(\mathbf{B})$ e ventral $(\mathbf{C})$; $\mathbf{D}-\mathbf{E}$, discos apicais. Escalas: $A, B, C=10$ $\mathrm{mm} ; \mathrm{D}, \mathrm{E}=1 \mathrm{~mm}$.

Figure 3. Leptosalenia sergipensis (FPH-806-I) in dorsal (A), lateral (B), and ventral (C) views; D- E, apical disc. Scale bars: A, B, C = 10 $\mathrm{mm} ; \mathrm{D}, \mathrm{E}=1 \mathrm{~mm}$. 
com o formato subtriangular a oval.

Região ambulacral. Região ambulacral estreita e pouco sinuosa. Poros ambulacrais uniseriados, exceto próximo ao peristômio, onde estão arranjados de forma bisserial ou até trisserial. As placas ambulacrais são bigeminadas e possuem um único tubérculo primário até o âmbitus; abaixo dele, em direção à região oral, podem ser observados pequenos grânulos entre os tubérculos primários. Próximo ao peristômio, as zonas de tubérculos se estreitam e os tubérculos primários diminuem de tamanho. Na região do âmbitus, seis a sete placas ambulacrais ficam opostas a uma placa interambulacral.

Região interambulacral. É larga e pode apresentar entre cinco a sete placas em uma coluna. Os tubérculos primários são grandes e elevados, com o mamelão perfurado e a plataforma crenulada. Os tubérculos são maiores na região do âmbitus, se tornando menores próximos ao perístoma. As auréolas são lisas e podem conter de cinco a sete tubérculos escrobiculares. Tubérculos secundários e grânulos ocupam o interior da zona interradial, que é bastante estreita.

Perístoma. É levemente invaginado; contorno circular cerca de $50 \%$ do diâmetro da carapaça.

\section{Ordem PHYMOSOMATOIDAE Mortense, 1904 Família PHYMOSOMATIDAE Pomel, 1883 Phymosoma binexilis (White, 1887)}

(Figura 4)

Material. FPH-800-I a FPH-802-I.

Distribuições geográfica e estratigráfica. Espécie conhecida anteriormente apenas do Albiano superior da Formação Riachuelo, Sergipe (Smith, 1991). Amplia aqui sua distribuição estratigráfica para as camadas do Albiano médio de Sergipe. Carapaça. Com o formato arredondado e deprimido nas regiões aboral e oral entre 30,0 e 31,0 mm de diâmetro e entre 10,0 e 11,0 mm de altura.

Região apical. Ausente.

Região ambulacral. É ligeiramente alargada na altura do âmbitus. As placas ambulacrais são compostas, sendo a maioria das placas próximas da superfície adoral quadrigeminadas. As demais placas, da superfície oral até um pouco acima do âmbitus, são compostas por um grande, crenulado e não perfurado tubérculo primário, com aproximadamente cinco estrias, e que ocupa a maior parte da placa. O restante da área é ocupado por pequenos tubérculos secundários que ocorrem em ziguezague em uma faixa central da área ambulacral, e por pequenos grânulos entre eles e nas áreas adradiais. Os pares de poros são arranjados em arcos ou placas no âmbitus e abaixo dele; próximo ao peristômio, entretanto, estão organizados bisserialmente, formando filódios. Foram ainda observados seis a sete poros ambulacrais opostos a cada uma das placas interambulacrais na região do âmbitus.

Região interambulacral. É mais larga do que a ambulacral. As placas inter-radiais são estreitas e sustentam um grande tubérculo primário não perfurado e dois, três ou quatro tubérculos secundários menores. Foi possível contar cerca de 10 placas em cada coluna. A auréola dos tubérculos primários é alta e lisa com plataforma levemente crenulada.

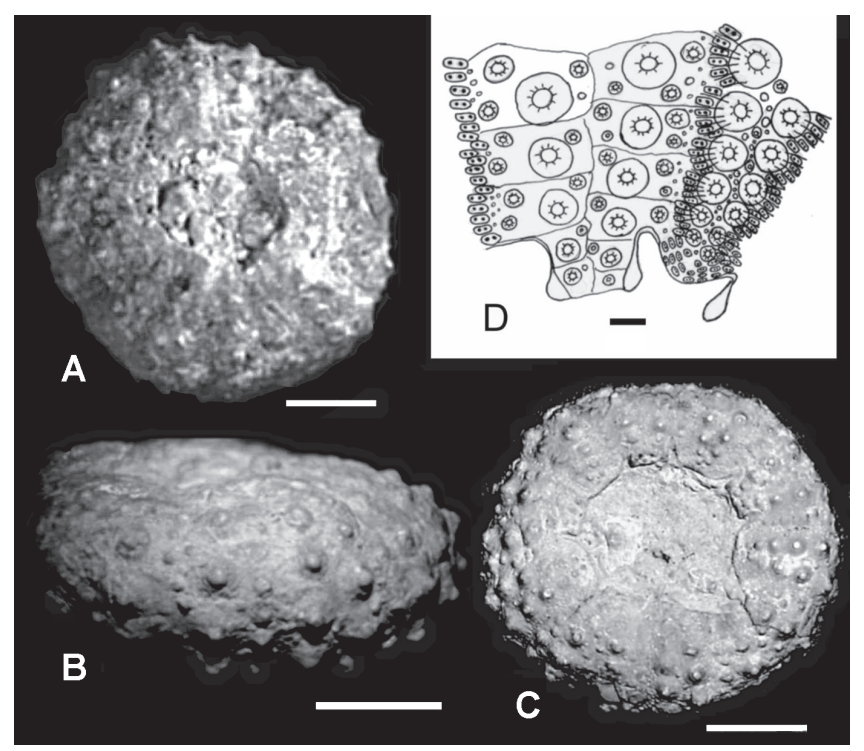

Figura 4. Phymosoma binexilis (FPH-800-I) em vistas dorsal (A), lateral (B), e ventral (C); $\mathbf{D}$, placas interambulacrais e ambulacrais. Escalas: A, B, C = $10 \mathrm{~mm}$; $\mathrm{D}=1 \mathrm{~mm}$.

Figure 4. Phymosoma binexilis (FPH-800-I) in dorsal (A), lateral (B), and ventral (C) views; D, interambulacral and ambulacral plates. Scale bars: $A, B, C=10 \mathrm{~mm} ; D=1 \mathrm{~mm}$.

As duas fileiras de tubérculos primários convergem em direção ao perístoma e são separadas por tubérculos secundários e grânulos. Os tubérculos secundários são mais comuns na região do perístoma até um pouco acima do âmbitus. Em direção à região apical, estes tubérculos tornam-se mais escassos.

Perístoma. Tem o formato arredondado e não invaginado.

\author{
Ordem HOLECTYPOIDA Ducan, 1889 \\ Família HOLECTYPIDAE Lambert, 1899 \\ Coenholectypus neocomiensis (Gras, 1848)
}

(Figura 5)

Material. FPH-818-I a FPH-822-I; FPH-823-I a FPH-832-I. Distribuições geográfica e estratigráfica. Espécie com ampla distribuição geográfica e estratigráfica, aparecendo nos registros do Aptiano ao Cenomaniano da Europa, Oriente médio, África e América. Em Sergipe esta espécie é Abundante no Albiano Superior da Formação Riachuelo e no Cenomaniano inferior da Formação Cotinguiba.Aqui Coenholectypus neocomiensis é registrada pela primeira vez para o Albiano médio da Formação Riachuelo em Sergipe

Carapaça. De formato subcônico e com contorno pentagonal, entre 11,0 e 32,0 mm de diâmetro onde a altura corresponde à cerca de $30 \%$ do diâmetro da carapaça.

Região apical. É pequena e formada por cinco placas genitais e cinco placas oculares. A placa genital 2 (madreporita) é bastante desenvolvida e ligeiramente mais alta do que as demais placas, e ocupa todo o centro do disco.

Região ambulacral. As placas acima do âmbitus são formadas por duas séries de placas estreitas, ligeiramente intercaladas na região mediana. Cada uma destas placas possui um tubérculo primário pequeno, com mamelão perfurado. Em 


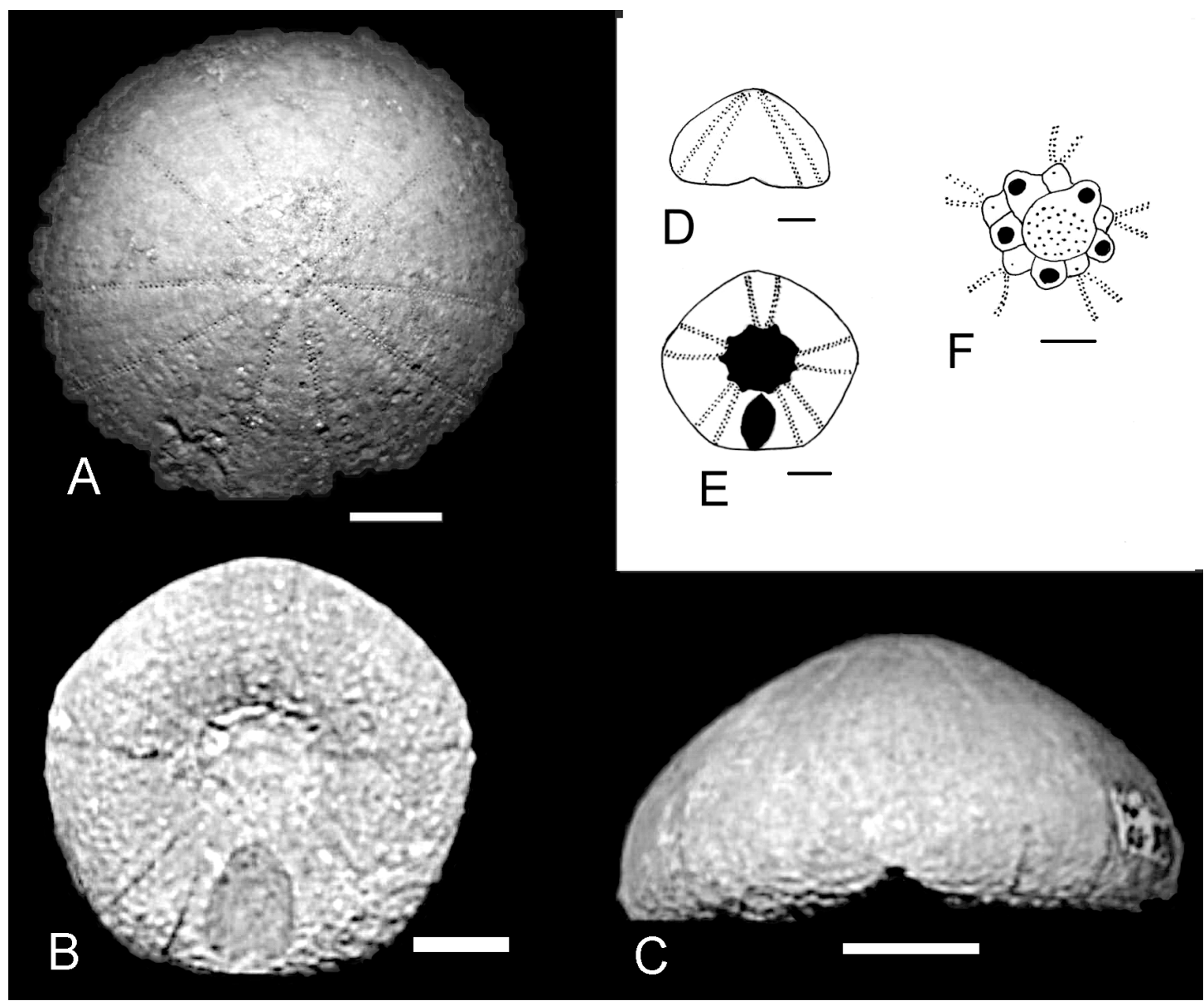

Figura 5. Coenholectypus neocomiensis (FPH-826-I): A, vista dorsal; B, E, vista ventral; C, D, vista lateral; F, disco apical. Escalas: A-E $=10 \mathrm{~mm} ; \mathrm{F}=1 \mathrm{~mm}$.

Figure 5. Coenholectypus neocomiensis (FPH-826-I): A, dorsal view; B, E, ventral view; C, D, lateral view; F, apical disc. Scale bars: A$\mathrm{E}=10 \mathrm{~mm} ; \mathrm{F}=1 \mathrm{~mm}$

algumas placas, este tubérculo está situado ao lado dos poros ambulacrais, e em outras, no meio da placa, ou ainda próximo à placa adjacente. Cerca de dois a seis grânulos podem ser observados espalhados sobre as placas. A região abaixo do âmbitus possui tubérculos primários maiores do que os aborais. Estes tubérculos estão dispostos irregularmente em cada placa. Nos exemplares examinados, foi encontrada uma média de 90 pares de poros ambulacrais em cada coluna.

Região interambulacral. Com placas maiores do que aquelas da região ambulacral. Estas placas possuem tubérculos com mamelão perfurado, que são maiores e mais numerosos próximos ao âmbitus, onde foi encontrada uma média de sete a nove tubérculos por placa.

Periprocto. É grande, de formato oval e ocupa a maior parte da região oral posterior, entre o âmbitus e o perístoma.

Perístoma. Tem um raio de comprimento aproximado ao comprimento do periprocto.

\section{ASPECTOS TAFONÔMICOS E PALEOECOLÓGICOS}

O endoesqueleto dos equinóides é composto por placas calcíticas encaixadas e por um tecido conectivo mutável (TCM) que aumenta sua viscosidade em poucos segundos e até 100 vezes mais que aquela existente no estado relaxado, quando o animal está vivo, dificultando a ação de predadores que tentam quebrar a carapaça para a ingestão do seu conteúdo (Smith, 1984; Hadel et al., 1999). Após a morte do animal, o TCM se decompõe, mas as placas permanecem ainda unidas por um tempo maior. O tempo de separação destas placas, no entanto depende da quantidade de tecido entre elas (Smith, 1984). De acordo com Smith (1984), há uma relação direta entre o estado de preservação da carapaça dos equinóides e o modo como os indivíduos morreram. Algo dessa relação pode ser observada na fauna fóssil de equinóides de Catete Velho 1. As carapaças de Orthopsis miliaris, a espécie mais abundante neste afloramento, mostram as placas dos sistema apical preservadas, mas não as placas peristomiais, a maioria dos espinhos e a Lanterna de Aristóteles, sugerindo que o animal não foi soterrado abruptamente após a morte, por ocasião de eventos de tormentas ou outros processos de sedimentação episódica (Smith, 1984). Incrustações por tubos de serpulídeos observadas em algumas carapaças, reforçam a idéia de permanência das mesmas expostas sobre o substrato por certo tempo antes de seu total soterramento. Outro fato observado foi à presença de formas juvenis encontradas no que aparentemente seria o mesmo hábitat da população adulta e 
assim como eles mantiveram as placas do sistema apical.

De um modo geral a preservação das carapaças de equinóides regulares fósseis é bem menor do que as dos irregulares. Segundo Kier (1977), isto ocorre pelo fato de a maioria destas espécies ter vivido em áreas de erosão ativa onde teriam pouca chance de preservação. De acordo com as características observadas nas carapaças encontradas na localidade Catete Velho1, provavelmente estas espécies estiveram distribuídas em substratos que variaram entre duros e móveis. As carapaças também mostraram características de adaptação a um ambiente protegido, longe da ação das ondas e correntes, como filódios muito curtos com poros denunciando uma fraca inserção de músculos que não seriam fortes o suficiente para se fixarem no substrato sob ação de fortes ondas e correntes, ou mesmo por carapaças sem filódios. Ainda, as placas da grande maioria de suas carapaças foram encontradas articuladas e bem preservadas, o que não teria sido possível em um ambiente de alta energia.

O intervalo Aptiano-Albiano foi um período de importantes transformações na bacia de Sergipe-Alagoas, sendo marcado por subidas e descidas do nível do mar que deixaram reflexos na distribuição da fauna marinha (Koutsoukos et al., 1991). Este período também foi de evolução para muitos grupos de equinóides, possibilitando a conquista de novos hábitats. Na bacia de Sergipe-Alagoas, estes hábitats parecem ter sido ocupados por várias formas de equinóides durante o Albiano inferior e Superior (Manso \& Souza-Lima, 2003a, 2003b, 2005).

A morfologia das estruturas da carapaça dos equinóides desempenha um papel importante na sua fisiologia e, em conseqüência, na sua relação com diferentes hábitats (Néraudeau et al., 1993; Smith, 1978, 1980, 1994, 1995; Manso, 2003). A grande maioria dos exemplares preservados no afloramento Catete Velho 1 mostram carapaça baixa com maior exposição dos pódios respiratórios e filódios curtos (Tabela 1), o que permite alocar as espécies reconhecidas em um contexto paleoambiental raso e de águas calmas, possivelmente relacionado a uma laguna protegida por recifes e rochas.
A posição do perístoma nas demais carapaças revelou os diferentes hábitos tróficos e, com base neles, a distribuição dos espécimes na paleolaguna mesoalbiana preservada em Catete Velho 1. Espécies como Orthopsis miliaris e Leptosalenia sergipensis, que continham perístoma pouco invaginado, provavelmente devem ter preferido fundos estabilizados, onde pudessem se alimentar de algas, plantas marinhas, pequenos animais e detritos do substrato. Por outro lado, a presença de perístoma mais plano em Phymosoma binexilis, sugere que esta espécie teria se alimentado raspando algas e pequenos animais incrustados nas rochas.

$\mathrm{O}$ enorme periprocto observado em Coenholectypus neocomiensis evidencia um metabolismo que resulta na eliminação constante de grandes partículas fecais e sugere a ingestão de partículas de detritos orgânicos junto com sedimento, a partir dos movimentos da Lanterna de Aristóteles. Assim, é possível que C. neocomiensis tenha vivido pouco enterrada ou sobre sedimentos formados por areia grossa ou cascalho. De acordo com Smith (1984), Coenholectypus teria tido o comportamento similar ao moderno holectipóide do gênero Echinoneus, que não possui pódios especializados para trocas gasosas, ficando praticamente imóvel durante o dia sob cascalho ou areia grossa, e saindo à noite em busca de alimento. Smith (1995) encontrou Coenholectypus entre a fauna de equinóides do Cretáceo superior na Península Arábica e sugeriu que, assim como Echinoneus, possivelmente esse gênero tenha vivido em ambientes localizados atrás das franjas de recifes. Assim, a presença de Coenholectypus na fauna de Catete Velho 1 sugeriria uma possível influência recifal próxima. Contudo, não foram encontradas grandes construções recifais nos depósitos da Formação Riachuelo, apenas patch reefs isolados, às vezes associados a corais.

\section{CONSIDERAÇÕES FINAIS}

As características morfológicas dos equinóides da localidade Catete Velho 1, evidenciaram a existência de um ambiente calmo, raso e protegido, possivelmente posicionados

Tabela 1. Principais características morfológicas das espécies na localidade Catete Velho I e seus possíveis habitats (de acordo com Smith, 1995 e Manso, 2003).

Table 1. Main features of the species occurring in Catete Velho I and their possible habitats (according to Smith, 1995 and Manso, 2003).

\begin{tabular}{|c|c|c|c|c|c|}
\hline Espécie & Carapaça & Ambulacros & Peristoma & Periprocto & Paleohabitat \\
\hline $\begin{array}{l}\text { Temnocidaris } \\
\text { (Stereocidaris) } \\
\text { malheiroi }\end{array}$ & Globular & $\begin{array}{l}\text { Poros conjugados a } \\
\text { subconjugados }\end{array}$ & $\begin{array}{l}\text { Levemente } \\
\text { invaginado }\end{array}$ & $\begin{array}{l}\text { No interior do } \\
\text { sistema apical }\end{array}$ & $\begin{array}{l}\text { Sem ondas, } \\
\text { disponibilidade de } \\
\text { matéria orgânica }\end{array}$ \\
\hline $\begin{array}{l}\text { Orthopsis } \\
\text { miliaris }\end{array}$ & Baixa & $\begin{array}{l}\text { Com poucos } \\
\text { Filódios }\end{array}$ & $\begin{array}{l}\text { Levemente } \\
\text { invaginado }\end{array}$ & $\begin{array}{l}\text { No interior do } \\
\text { sistema apical }\end{array}$ & $\begin{array}{l}\text { Protegido, raso, em } \\
\text { ou próximo a fundos } \\
\text { estabilizados. }\end{array}$ \\
\hline $\begin{array}{l}\text { Leptosalenia } \\
\text { sergipensis }\end{array}$ & Baixa & $\begin{array}{l}\text { Poros aborais mais } \\
\text { numerosos e } \\
\text { especializados para } \\
\text { trocas gasosas }\end{array}$ & $\begin{array}{l}\text { Levemente } \\
\text { invaginado }\end{array}$ & $\begin{array}{l}\text { No interior do } \\
\text { sistema apical }\end{array}$ & $\begin{array}{l}\text { Protegido, sem o } \\
\text { efeito de ondas, em } \\
\text { ou próximo a fundos } \\
\text { estabilizados }\end{array}$ \\
\hline $\begin{array}{l}\text { Phymosoma } \\
\text { binexilis }\end{array}$ & $\begin{array}{l}\text { Deprimida (dorsal- } \\
\text { ventral) }\end{array}$ & $\begin{array}{c}\text { Poros da região oral } \\
\text { formando filódios } \\
\text { curtos }\end{array}$ & Não invaginado & $\begin{array}{l}\text { No interior do } \\
\text { sistema apical }\end{array}$ & $\begin{array}{c}\text { Protegido, raso, em } \\
\text { substrato } \\
\text { consolidado. }\end{array}$ \\
\hline $\begin{array}{l}\text { Conholectipus } \\
\text { neocomiensis }\end{array}$ & $\begin{array}{c}\text { Subcônica/ } \\
\text { Subpentagonal, } \\
\text { tubérculos pouco } \\
\text { maiores na região oral }\end{array}$ & $\begin{array}{l}\text { Iguais, com os } \\
\text { pares de poros em } \\
\text { fileira única }\end{array}$ & Grande & Adoral, grande & $\begin{array}{c}\text { Cascalho e/ou areia } \\
\text { grossa próximo a } \\
\text { recifes }\end{array}$ \\
\hline
\end{tabular}


atrás de bancos carbonáticos no Albiano médio na bacia de Sergipe-Alagoas. As espécies que viveram ali, possuíram estruturas na carapaça que apontaram para estratégias específicas de obtenção de alimento, demonstrando a possibilidade de existência de diferentes hábitats.

\section{AGRADECIMENTOS}

As autoras agradecem à Fundação Paleontológica Phoenix, pelo empréstimo do material estudado; a W. S. Lima, pelo auxílio nas fotografias de L. sergipensis; à Universidade Federal de Sergipe pela bolsa (CLCM) do Programa de Auxílio à Integração de Docentes e Técnicos Administrativos RecémDoutores às Atividades de Pesquisa; e ao CNPq-PIBIC pela bolsa de Iniciação Científica (ACCL).

\section{REFERÊNCIAS}

Archiac, J.A. d' 1835. Mémoire sur la Formacion Crétacée du Sud Ouest de la France. Mémoires de la Societé géologique de France, série 1, 2:157-192.

Bengtson, P. 1983. The Cenomanian-Coniacian of the Sergipe Basin, Brazil. Fossila and Strata, 12:1-78.

Brito, I.M. 1964. Equinóides cretácicos do Estado da Bahia. Salvador, Escola de Geologia, Universidade Federal da Bahia, 11 p. (Publicações Avulsas 1).

Brito, I.M. 1980a. Os Equinóides fósseis do Brasil: I. Os endocíclicos. Anais da Academia Brasileira de Ciências, 52(3):569-590.

Brito, I.M. 1981b. Os equinóides fósseis do Brasil: II. Holectipóides e Cassidulóides. Anais da Academia Brasileira de Ciências, 53(3):513-527.

Brito, I.M. \& Ramirez, L.V.O. 1974. Contribuição ao conhecimento dos equinóides albianos (Cretáceo inferior) do Brasil. Anais da Academia Brasileira de Ciências, 46(2):275-282.

Dartavelle, E. 1953. Échinides fossiles du Congo et de l'Angola. Deuxieme Partie, Description systématique dês échinides fossiles du Congo et de 1'Angola. Annales du Musée Royal du Congo Belge, 13:1-240.

Feijó, F.J. 1994. Bacias de Sergipe e Alagoas. Boletim de Geociências da Petrobras, 8(1):149-153 .

Gras, C.J.A. 1848. Description des oursins fossiles du département de 1'Isère. Bulletin de la Societé de Statistique des Sciences Naturelles et des Arts Industriels du Département de l'Isère, Première Série, 4:293-381.

Hadel, V.F.; Monteiro, A.M.G.; Ditadi, A.S.F.; Tiago, C.G.\& Tommasi, L.R.1999. Echinodermata. In: A.C. Migotto \& C.G. Thiago (eds.) Biodiversidade do estado de São Paulo, Brasil. 3. Invertebrados Marinhos, FAPESP, p. 260-271.

Hendler, G.; Miller, J.E.; Pawson, D.L. \& Kier, P.M. 1995. Sea stars, sea-urchins and allies: echinoderms of Flórida and the Caribbean. $1^{\text {a }}$ ed. Washington D.C., Smithsonian Press, 392 p.

Kier, P.M. \& Grant, R.E. 1965. Echinoids distribution and habits, Key Largo Coral Reef Preserve, Florida. Smithsonian Miscellaneous Collections, 149(6):1-68.

Koutsoukos, E.A.M.; Mello, M.R.; Azambuja Filho, N.C.; Hart, M.B. \& Maxwell, J.R. 1991. The upper Aptian-Albian sucession off the Sergipe Basin, Brazil: an integrated paleoenviromental assessment. American Association Petroleum Geologist Bulletin, 75(3):479-498.
Koutsoukos, E.A.M.; Destro, N.; Azambuja Filho, N.C.; Spadini, A.R. 1993. Upper Aptian-lower Coniacian carbonate sequences in the Sergipe Basin. Northeastern Brazil. In: J.A.T. Simo; R.W. Scott \& J.P. Masse (eds.) Atlas of Cretaceous carbonate platforms, American Association of Petroleum Geologists Memoir 56, p. 127-144.

Lambert, J. 1927. Considerations sur lês Échinides de la Comanche serie du Texas. Bulletin de la Société Géologique de France, Serie 4, 26:263-278.

Lemos, A.C. \& Manso, C.L.C. 2007. Os equinóides (Echinodermata: Echinoidea) da localidade Catete Velho 1 (Cretáceo, Albiano) de Sergipe: resultados preliminares. Boletim Paleontologia em Destaque, 61:11-12.

Loriol, P. 1888. Matériaux pour 1'étude stratigrafique et paléontologique de la Province d'Angola. Description dês Échinides. Mémoires de la Société de physique e d'Histoire naturelle de Genève 30(2):97-114.

Manso. C.L.C. 2003. Paleoecologia, Paleobiogeografia e Sistemática dos Equinóides do Aptiano-Albiano (Cretáceo) do Brasil. Programa de Pós-graduação em Geologia, Universidade Federal da Bahia, Tese de doutorado, 206 p.

Manso.C.L.C. \& Souza-Lima, W. 2003a. O registro do equinóide Hemiaster zululandensis Besaire \& Lambert, 1930 no Cretáceo (Albiano Superior) de Sergipe. Revista Brasileira de Paleontologia, 6:61-67.

Manso, C.L.C. \& Souza-Lima, W. 2003b. O equinóide Douvillaster Lambert, 1917, na Formação Riachuelo, sub-bacia de Sergipe, Brasil. Revista Brasileira de Paleontologia, 5:29-37.

Manso. C.L.C. \& Souza-Lima, W. 2005. Os equinóides Pygorhynchus colombianus (Cook, 1955) e Pseudholaster altiusculus (White, 1887) no Neoalbiano da Bacia de Sergipe, Brasil. Revista Brasileira de Paleonotologia, 8(3):229-238.

Maury, C.J. 1937. O Cretaceo de Sergipe. Rio de Janeiro, Serviço Geológico e Mineralógico do Brasil, 283 p. (Monographia 11).

Néraudeau, D.; Buzón, G. \& Córnée, A. 1993. Lés échinides du Cénomanien supérieur et du Turonien inférieur du Tiurhert Oriental et central (Sahara, Algérien). Annales de Paléontologie, 79(4):273-313.

Ojeda, H.A.O. \& Fujita, M. 1976. Bacia Sergipe-Alagoas: Geologia Regional e perspectivas petrolíferas. In: CONGRESSO BRASILEIRO DE GEOLOGIA, 28, 1976. Resumos Expandidos, Porto Alegre, UFRGS, 2:137-158.

Reis, M.A.F.; Turbay, C.V.G. \& Cesero, P. De. 2005. Descrição de um novo Decapoda ( Natantia, Malacostraca, Crustacea) da Formação Riachuelo, Albiano da Bacia de Sergipe. Anuário do Instituto de Geociências da Universidade Federal do Rio de Janeiro, 28(1):80-91.

Roemer, F. 1852. Die Kreidebildungen von Texas und ihre organischen Einschluss. Bonn, Adolph Marcus, 100 p.

Schaller, H. 1970. Revisão estratigráfica da Bacia de SergipeAlagoas.Boletim Técnico da Petrobrás, 12(1):21-86.

Smith, A.B. 1984. Echinoid Palaeobiology. $1^{\mathrm{a}} \mathrm{ed}$. London, George Allen \& Unwin, 199 p.

Smith, A.B. 1995. Late Campanian-Maastrichtian echinoids from the United Arab Emirates-Oman border region. Bulletin of $\mathrm{Na}$ tural History Museum of London (Geology), 51(2):121-240.

Smith, A.B. \& Bengtson, P. 1991. Cretaceous echinoids from northeastern Brazil. Fossils and Strata, 31:1-88.

White, C.A. 1887. Contribuições à paleontologia do Brazil. Archivos do Museu Nacional do Rio de Janeiro, 7:1-273.

Received in April, 2008; accepted in August, 2008. 